\title{
The effect of using the monoclonal antibodies of the protein ErbB-2 antigen on the lung cancer patients
}

\author{
Dina Saeed Solitah, Mustafa Ashraf Salah \\ STEM Schools in EGYPT \\ lci.therapy.md@gmail.com
}

\author{
DOI: 10.29322/IJSRP.10.11.2020.p10758 \\ http://dx.doi.org/10.29322/IJSRP.10.11.2020.p10758
}

\begin{abstract}
Cancer is one of the most challenging diseases and up until now. One of the most challenging things about cancer treatment is not the cure itself but the differentiation between the tumor cells and the normal cells. Most of the medical treatments of the cancer today cannot differentiate between the cancer cells and the normal one as well as it damages the hall tissue and it is still considered as a low-effect treatment to be applied in cancer. One of the most popular treatments of this kind is chemotherapy which is known for damaging the hall cells, cancer, and normal ones. Our research is focusing on generating a new therapy that can target the cancer cell itself so it will give us more efficiency ratio to stop cancer and will keep the other cells without any damage. We will use an antibody body for the protein antigen ErbB-2 which is located rabidly in the lung cancer cells' membrane surface. These antibodies will be produced by the immune system so it will target the tumor cells especially and stop the cell growth and damage it in some cases.
\end{abstract}

Index Terms- Lung Cancer, ErbB-2 protein, Antigen, Complete blood count, Tumor marker test.

\section{INTRODUCTION}

$\mathrm{L}$ ung cancer is the leading cancer killer of both men and women. it also has one of the lowest five-year survival rates of all cancer types. Lung cancer causes the most cancer deaths worldwide, accounting for 2.1 million new cases and 1.8 million deaths annually. More than half of people with lung cancer die within one year of being diagnosed. In 1987, it surpassed breast cancer to become the leading cause of cancer deaths in women. There will be more than 234,000 new cases of lung cancer in 2018. These new cases accounted for more than 13 percent of all cancer diagnoses. Over the last 10 years, the number of deaths due to lung cancer has decreased about 28 percent among men, but only increased about 3 percent among women. According to these reasons we can conclude that the lung cancer has non efficient treatment. The problem of the cancer in general not only the lung cancer is in its therapy methods. Cancer has no effective therapy method or drug up till now. The most popular therapy method today for cancer is the chemotherapy. Chemotherapy is a drug treatment that uses powerful chemicals to kill fast-growing cells in your body. Chemotherapy is most often used to treat cancer, since cancer cells grow and multiply much more quickly than most cells in the body. There are many differ drugs of chemotherapy for the different kinds of cancer. Chemotherapy drugs can be used alone or in combination to treat a wide variety of cancers. In addition to that chemotherapy is an ineffective way to treat many types of cancer, chemotherapy treatment also carries a risk of many dangerous side effects. chemotherapy side effects damage the body tissues as well as it can develop to organ failures in many cases. Chemotherapy cannot differentiate between the normal cells and the tumor cells; it damages all the cells. Damaging of the normal cells cause most of these massive side effects. Cancer treatment is a very serious problem that researchers try to solve. Most of the researches today focus on finding out new therapies methods which can differentiate between the cancer cells and the tumor cells as a way of making the side effects becomes treatable. Cancer is the uncontrolled growth of abnormal cells anywhere in a body. These abnormal cells are termed cancer cells, malignant cells, or tumor cells. These cells can infiltrate normal body tissues. The mutation of the DNA which happens in genes during the division of the cell leads the cell to make uncontrolled division. The immune system responses to the cancer cell and damage it but only in the earlier phases. The immune response process consists of some action that the immune system takes to stop the tumor cells from growing. At first, Antigens is released from the tumor cells. The dendritic cells present the antigens which are released from the tumor cells to the T cells. After this, $\mathrm{T}$ cells are primed activated then, they traffic to tumor cells. After these actions, The $\mathrm{T}$ cells infiltrate into tumor to recognize and bind with the tumor cells. At the end after the B cells binds with the antigens, the antibodies of every specific antigen are created, and these antibodies binds with the tumor cells surface's antigens to kill the tumor cell. Cancer immunoediting process is envisaged to consist of three phases: elimination, equilibrium, and escape. In the Elimination phase, tumor cells are successfully recognized and eliminated by the immune system, thus returning the tissues to their normal state of function. Tumor cells that elude the immunosurveillance phase will progress to the immune editing phase, called the equilibrium phase of advanced oncogenesis, where tumor expansion and metastasis are minimal (tumor dormancy) and usually occur without symptoms.

\section{STUDY DESIGN}

Our study design is randomized control trail (RCT). RCT is a scientific medical experiment that aims to reduce certain sources of bias when testing the effectiveness of our therapy; this is accomplished by randomly allocating subjects to the two groups 
of our experiment, treating them differently, and then comparing them with respect to a measured response.

\section{SAMPLE SIZE AND SELECTION OF SAMPLE}

10 mice:

- Females.

- An albino laboratory mouse - BALB/c.

- In the middle age (10 month).

- Diagnosed with the lung cancer in the late phase (tumor represent $60 \%$ of tissues).

\section{DATA COLLECTION AND STUDY TOOL}

Monoclonal antibodies for Ebbr-2 antigen production Mono' means 'one' and 'clone' means 'identical copy'. Monoclonal antibodies are identical copies of one type of antibody.

Antibodies are proteins produced by a type of white blood called lymphocytes. Pathogens have proteins on their surface called antigens. When a pathogen infects the body, the lymphocytes recognize these antigens as foreign and attack them by producing antibodies.

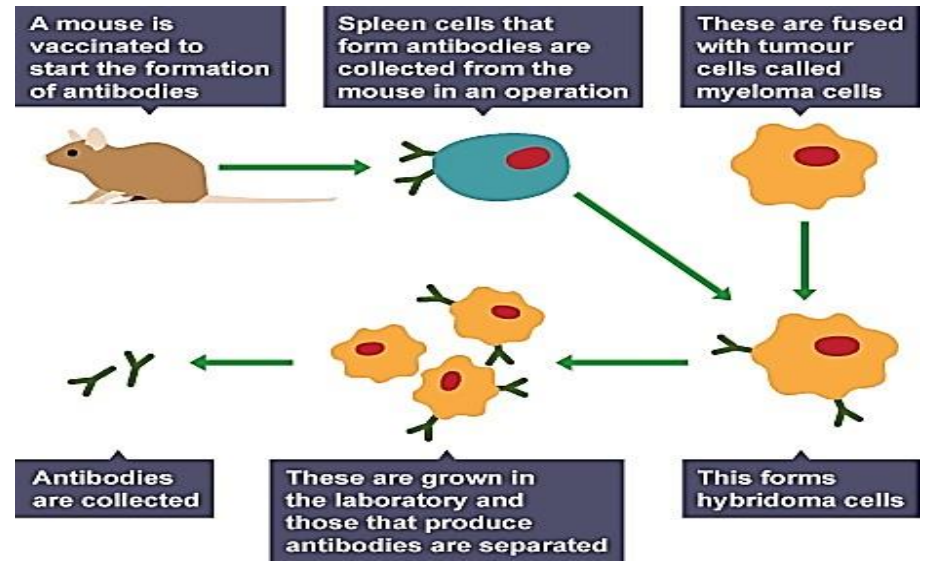

Antibodies bind to specific antigens on pathogens. This means that only one type of antibody will bind to a matching antigen. Scientists discovered that we could make antibodies to bind to antigens on other substances, and not just those on pathogens. Once bound, the antigens - and the substances they are found on are merged tightly together. This makes them easier to identify and deal with.

Formation of monoclonal antibodies:

1. The antigen is extracted from the cancer cells tumor by Elisa.

2. The Ebbr-2 antigen is injected into a mouse.

3 . The mouse naturally produces lymphocytes, which produce antibodies specific to the antigen.

4. Spleen cells which produce the lymphocytes are removed during a small operation.

5. The spleen cells are fused with human cancerous white blood cells called myeloma cells to form hybridoma cells which divide indefinitely.

6. These hybridoma cells divide and produce millions of monoclonal antibodies specific to the original antigen.

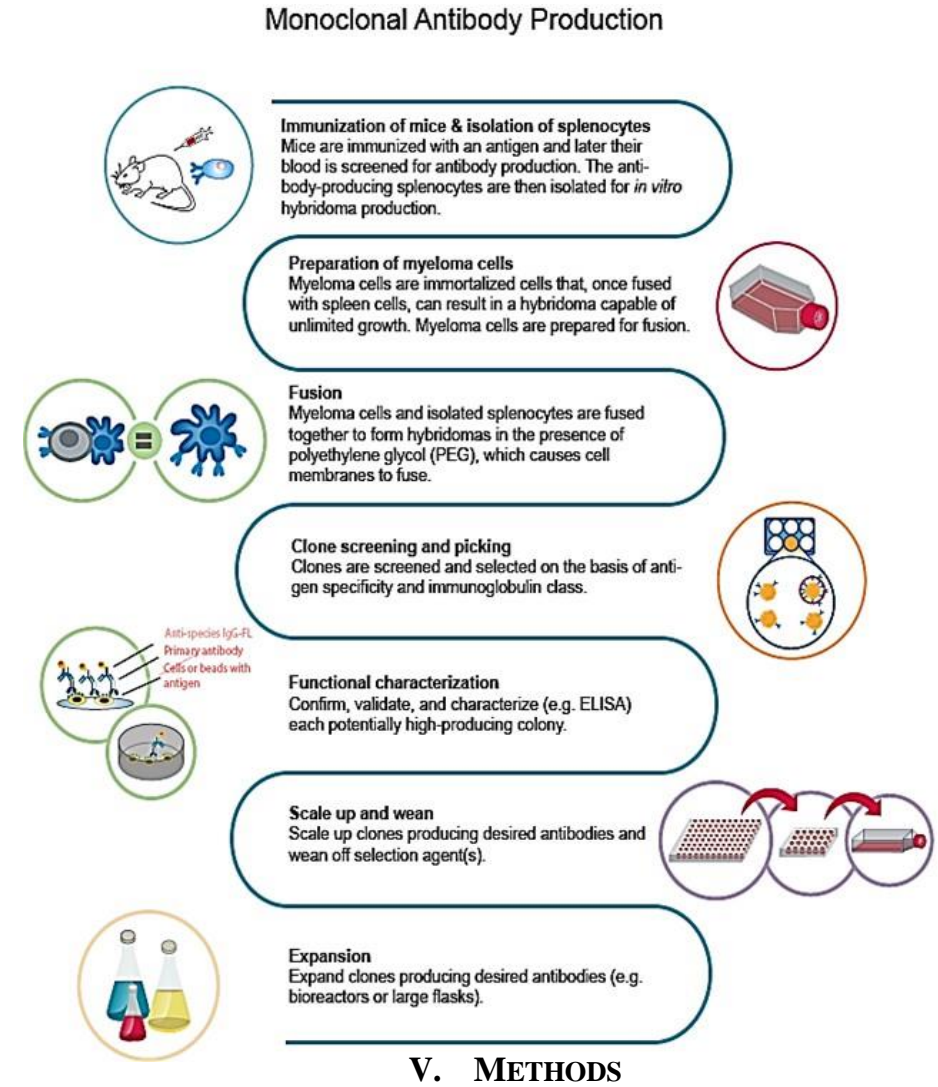

Observational:

The other common side effects for the therapy is observed during time of the experiment after applying the antibodies therapy compared with the other sample which has no therapy applied on:

- Weight loss.

- Lungs failure.

\section{Experimental:}

Our experiment extends for one month that all the next procedures is made:

- Complete blood count (CBC). This common blood test measures the amount of various types of blood cells in a sample of your blood. Blood cancers may be detected using this test if too many or too few of a type of blood cell or abnormal cells are found. A bone marrow biopsy may help confirm a diagnosis of a blood cancer.

- Blood protein testing. A test (electrophoresis) to examine various proteins in your blood can aid in detecting certain abnormal immune system proteins (immunoglobulins) that are sometimes elevated in people with multiple myeloma. Other tests, such as a bone marrow biopsy, are used to confirm a suspected diagnosis.

- Tumor marker tests. Tumor markers are chemicals made by tumor cells that can be detected in your blood.

- But tumor markers are also produced by some normal cells in your body, and levels may be significantly elevated in noncancerous conditions. This limits the potential for tumor marker tests to help in diagnosing cancer. Only in extremely rare circumstances would such 
a test be considered enough to make a firm diagnosis of cancer.

- The best way to use tumor markers in diagnosing cancer hasn't been determined. And the use of some tumor marker tests is controversial.

- Examples of tumor markers include prostate-specific antigen (PSA) for prostate cancer, cancer antigen 125 (CA 125) for ovarian cancer, calcitonin for medullary thyroid cancer, alpha-fetoprotein (AFP) for liver cancer and human chorionic gonadotropin (HCG) for germ cell tumors, such as testicular cancer and ovarian cancer.

- Circulating tumor cell tests. Recently developed blood tests are being used to detect cells that have broken away from an original cancer site and are floating in the bloodstream. One circulating tumor cell test has been approved by the Food and Drug Administration to monitor people with breast, colorectal or prostatecancer. This test isn't commonly used in a clinical setting.

- Test results must be interpreted carefully because several factors can influence test outcomes, such as variations in the body or even the food.

\section{DATA ANALYSIS Plan AND DATA PRESENTATION}

Data is analyzed by Microsoft adobe excel through T-test measuring the difference between results of PCR and antibodies at a level of significance (0.05).

\section{TIMELINE}

\begin{tabular}{|l|l|}
\hline \multicolumn{1}{|c|}{ TIMELINE } & \multicolumn{1}{c|}{ DAYS } \\
\hline CBC test & $20=>120$ \\
\hline Blood protein testing & First 30 days \& last 30 days \\
\hline $\begin{array}{l}\text { Monoclonal } \\
\text { antibodies production }\end{array}$ & 20 \\
\hline Tumor marker tests & $90=>120$ \\
\hline $\begin{array}{l}\text { Circulating tumor } \\
\text { cell test }\end{array}$ & 70 \\
\hline $\begin{array}{l}\text { Monoclonal } \\
\text { antibodies injection }\end{array}$ & At 20 \\
\hline Evaluation tumor & 30 \\
\hline Analysis & $1-2$ (through two days) \\
\hline Total time & 120 days \\
\hline
\end{tabular}

\section{ACKNOWLEDGMENTS}

We thank Allah for supporting us and we are delighted to honor those who helped us in any stage of the Project especially Dr. Mai Mansour, Mrs. Gehan Mohamed, Mrs. Noha Anber, National Research Centre - NRC, 57357 Hospital, STEM Community.

\section{REFERENCES}

[1] Adam, J.K., Odhav, B., Bhoola, K.D., 2003. Immune responses in cancer. Pharmacology and Therapeutics 99, 113-132. doi:10.1016/S0163 7258(03)00056-1

[2] Gonzalez, H., Hagerling, C., Werb, Z., 2018. Roles of the immune system in cancer: From tumor initiation to metastatic progression. Genes and Development. doi:10.1101/GAD.314617.118

[3] Korman, A.J., Peggs, K.S., Allison, J.P., 2006. Checkpoint Blockade in Cancer Immunotherapy. Advances in Immunology. doi:10.1016/S00652776(06)90008-X

[4] Håkansson, L., 2009. The capacity of the immune system to control cancer. European Journal of Cancer. doi:10.1016/j.ejca.2009.06.002

[5] Dunn, G.P., Koebel, C.M., Schreiber, R.D., 2006. Interferons, immunity and cancer immunoediting. Nature Reviews Immunology.doi:10.1038/nri1961

[6] Teng, M.W.L., 2008. Immune-mediated dormancy: an equilibrium with cancer. Journal of Leukocyte Biology 84, 988-993. doi:10.1189/jlb.1107774

[7] Dunn, G.P., Old, L.J., Schreiber, R.D., 2004. The Three Es of Cancer Immunoediting. Annual Review of Immunology 22, 329-360. doi:10.1146/annurev.immunol.22.012703.104803

[8] Bhatia, A., Kumar, Y., 2011. Cancer-immune equilibrium: Questions unanswered. Cancer Microenvironment. doi:10.1007/s12307-011-0065-8

[9] Schiller, J.H., Harrington, D., ... Johnson, D.H., 2002. Comparison of four chemotherapy regimens for advanced non-small-cell lung cancer. New England Journal of Medicine 346, 92-98. doi:10.1056/NEJMoa011954

[10] Why your doctor might order a cancer blood test. (2019, December 10). Retrieved January 07, 2020, from https://www.mayoclinic.org/diseasesconditions/cancer/in-depth/cancer-diagnosis/art-20046459

[11] Cancer blood tests: Lab tests used in cancer diagnosis. (n.d.). Retrieved January 07, 2020, from https://www.drugs.com/mca/cancer-blood-tests-labtests-used-in-cancer-diagnosis

[12] Monoclonal antibodies - Higher - How can we identify the cause of an infection? - OCR 21C - GCSE Biology (Single Science) Revision - OCR 21st Century - BBC Bitesize. (n.d.). Retrieved January 07, 2020, from https://www.bbc.co.uk/bitesize/guides/zygn97h/revision/6

[13] Production of monoclonal antibodies - Higher Tier - Monoclonal antibodies - Higher - AQA - GCSE Biology (Single Science) Revision - AQA - BBC Bitesize. (n.d.). Retrieved January 07, 2020, from https://www.bbc.co.uk/bitesize/guides/zt8t3k7/revision/1

[14] How Serious Is Lung Cancer? (n.d.). Retrieved January 07, 2020, from https://www.lung.org/lung-health-diseases/lung-disease-lookup/lungcancer/learn-about-lung-cancer/what-is-lung-cancer/how-serious-is-lungcancer

[15] Immunopaedia. (n.d.). Retrieved January 07, 2020, from https://www.immunopaedia.org.za/immunology/special-focus-area/2cancer-tumours/immune-responses-to-cancer/

[16] Z; G. (n.d.). Roles of the immune system in cancer: From tumor initiation to metastatic progression. (2018, October 1). Retrieved January 07, 2020, from https://pubmed.ncbi.nlm.nih.gov/30275043/

\section{AUTHORS}

First Author -Dina Saeed Solitah, Maadi STEM School for Girls, +20 1129552145 and Denasalith@gmail.com.

Second Author -Mustafa Ashraf Salah, Obour STEM School, +201008578666 and Mostafaashraf348@gmail.com 